\title{
Microwave Dried Carrot Pomace as a Source of Fiber and Carotenoids
}

\author{
Marcela Hernández-Ortega ${ }^{1}$, Guy Kissangou ${ }^{1}$, Hugo Necoechea-Mondragón ${ }^{2}$, \\ María Elena Sánchez-Pardo ${ }^{1}$, Alicia Ortiz-Moreno ${ }^{1}$ \\ ${ }^{1}$ Departamento de Ingeniería Bioquímica, Escuela Nacional de Ciencias Biológicas, Instituto Politécnico Nacional, México City, \\ México; ${ }^{2}$ Coordinación de Cooperación Académica, Edificio de la Secretaría Académica, Instituto Politécnico Nacional, México City, \\ México. \\ Email: ortizalicia@hotmail.com, aortizm@ipn.mx
}

Received August $1^{\text {st }}, 2013$; revised September $1^{\text {st }}, 2013$; accepted September $8^{\text {th }}, 2013$

Copyright (C) 2013 Marcela Hernández-Ortega et al. This is an open access article distributed under the Creative Commons Attribution License, which permits unrestricted use, distribution, and reproduction in any medium, provided the original work is properly cited.

\begin{abstract}
Carrot pomace is a major by-product obtained during the industrial juice extraction process, which is discarded contributing to environmental pollution. This residue is rich in fiber, and contains high amounts of carotenoids and phenolic compounds that could contribute to its application as functional ingredient, improving the quality of foods and helping to reduce the environmental problem. In this study, carrot pomace powders obtained by microwave or hot air drying were incorporated into cookies in order to improve their phytochemical content. Cookies were prepared using a traditional cookie recipe substituting $30 \%$ of the wheat flour for either of the carrot pomace powders. Fiber, carotenoids and phenolic compounds were determined; image analysis and acceptability of the cookies were also conducted. The substitution of $30 \%$ of wheat flour for carrot pomace powders increased 3.7 fold the total dietary fiber of cookies, from $7.13 \mathrm{~g} / 100 \mathrm{~g}$ to $26.44 \mathrm{~g} / 100 \mathrm{~g}$; accounting the $7.4 \%$ of fiber daily intake with the consumption of one cookie $(7 \mathrm{~g})$. A similar pattern was found in the content of carotenoids and phenolic compounds. Carrot pomace dried with microwaves had the highest amount of these bioactive compounds. $\beta$-carotene, epicatechin, gallic and ferulic acids were identified in cookies with microwave carrot pomace powder. The cookies incorporated with carrot pomace powders exhibited improved antioxidant properties because of the increase in the phytochemical content. Acceptable cookies with appealing orange color were obtained. The results indicated that the replacement of wheat flour for carrot pomace powders yielded dietary fiber enriched cookies with improved carotenoid content.
\end{abstract}

Keywords: Carrot Pomace; Microwave; Drying; Fiber; Carotenoids; Phenolic Compounds; Antioxidant Activity; Cookie

\section{Introduction}

In carrot juice production up to $50 \%$ of the raw material remains as pomace which is mainly disposed as feed or manure. However, this pomace contains large amounts of valuable compounds such as carotenoids, dietary fiber [1], uronic acids and neutral sugars [2]. Sometimes the pomace has posed environmental problems; therefore, new technologies are needed to decrease the problem [3-6]. These could profitably be used to develop value added products with optimal phytochemical and fiber content without scarifying taste or convenience, not only providing nutritious products but also aiding in efficient utilization of carrot pomace, reducing environmental problems [7].
Recently food industries are being forced by governments to develop productions without secondary residues. Therefore, there is a considerable emphasis on the recovery, recycling and upgrading their by-products. Since these by-products antioxidant activities [8-11], and could be converted into a range of commercial products $[12,13]$. For these reasons, different researches have assayed different methods in order to obtain new raw materials products from fruit and vegetable processing by-products [14].

Although consumers are increasingly aware of diet related health problems, a large group of the population lacks a generous intake of fruits and vegetables [15]. This change in diet habits is related with the prevalence 
of different diseases. The dramatically increasing prevalence of obesity, especially among children, has become a major public health problem [16]. Overweight conditions in childhood are associated with increased risk for chronic diseases and other health concern $[17,18]$.

A broad range of activities and initiatives are currently being implemented to control pediatric and adult obesity, among these, improving the nutritional value of foodstuff is a key area [16].

Wheat bread and cookies are widely accepted and consumed in many developing countries offering a valuable supplementation vehicle for children nutritional improvement; however, cookies have been suggested for many authors as a better use of composite flour than bread because of their ready-to-eat form, wide consumption and relatively long shelf-life [19]. Recently cookies have been added with different types of fibers from vegetable and fruit sources in order to increase the fiber content, improve the texture, reduce the energy content and improve the color and aroma of the final product [20].

The objective of our study was to use the carrot pomace dried (CPD) in microwave oven or conventional oven as an ingredient in a cookie formulation to increase fiber and phytochemical content.

\section{Materials and Methods}

Carrots were purchased from a local market in Mexico City and the carrot pomace was obtained from juice extraction (Juice extractor, Moulinex 753, Mexico). It was obtained a $51.6 \%$ of juice and $48.4 \%$ of carrot pomace.

\subsection{Microwave Drying, Experimental Design}

Response Surface Methodology (RSM) was used to find the best microwave drying conditions. The independent factors were powder $(595,700$, and 770 Watts), and time $(15,20$, and $25 \mathrm{~min})$. The responses were moisture $\left(\mathrm{Y}_{1}\right)$, temperature $\left(\mathrm{Y}_{2}\right)$ and color parameter $\mathrm{a}^{*}\left(\mathrm{Y}_{3}\right)$ of carrot pomace. Actual and coded values of variation levels are shown in Table 1. An orthogonal routable central composite design, for $\mathrm{K}=2$ factors, was used resulting in 13 combinations, which were distributed as follows: 4 kernel points, 4 star points, and 5 replications at the central point, the design is presented in Table 2. The Equation (1) of linear regression of optimal response was calculated by a second-degree polynomial equation using the method of least squares:

$$
\mathrm{Y}=\mathrm{a}_{0}+\mathrm{a}_{1} \mathrm{~A}+\mathrm{a}_{2} \mathrm{~B}+\mathrm{a}_{11} \mathrm{~A}^{2}+\mathrm{a}_{22} \mathrm{~B}^{2}+\mathrm{a}_{12} \mathrm{AB}
$$

where $\mathrm{Y}$ is the response calculated by the model; $\mathrm{A}$ and $B$ are variables; linear regression coefficients are: $a_{1}, a_{2}$; the quadratics are $\mathrm{a}_{11}, \mathrm{a}_{22}$, and $\mathrm{a}_{12}$ the cross-product effects of two factors on the response.
Table 1. Independent variables and their coded and actual values used for microwave dehydration.

\begin{tabular}{cccccc}
\hline \multirow{2}{*}{ Factor } & \multicolumn{5}{c}{ Code/uncoded variables levels } \\
\cline { 2 - 6 } & -1.414 & -1 & 0 & 1 & 1.414 \\
\hline${ }^{1} \mathrm{~A}(\mathrm{~min})$ & 13 & 15 & 20 & 25 & 27 \\
${ }^{2} \mathrm{~B}(\mathrm{~W})$ & 560 & 595 & 700 & 770 & 805 \\
\hline
\end{tabular}

${ }^{1}$ is the drying time in the microwave; ${ }^{2}$ is the powder of the microwave.

Table 2. Central composite design arrange and responses: moisture $\left(Y_{1}\right)$, temperature $\left(Y_{2}\right)$ and color $\left(Y_{3}\right)$ for all tested CPPs dried in microwave oven.

\begin{tabular}{cccccc}
\hline $\begin{array}{c}\text { Run } \\
\mathrm{nr}\end{array}$ & $\begin{array}{c}{ }^{\mathrm{1}} \mathrm{A}: \\
\text { Actual } \\
\text { value }\end{array}$ & $\begin{array}{c}{ }^{2} \mathrm{~B}: \\
\text { Actual } \\
\text { value }\end{array}$ & $\begin{array}{c}\mathrm{Y}_{1} \\
(\mathrm{~g} / 100 \mathrm{~g})\end{array}$ & $\begin{array}{c}\mathrm{Y}_{2} \\
\left({ }^{\circ} \mathrm{C}\right)\end{array}$ & $\begin{array}{c}\mathrm{Y}_{3} \\
(\mathrm{URR})\end{array}$ \\
\hline 1 & 15 & 595 & 49.94 & 77.2 & 18.7 \\
2 & 25 & 595 & 6.73 & 110.2 & 12.6 \\
3 & 15 & 770 & 40.25 & 75.2 & 12.3 \\
4 & 25 & 770 & 1.08 & 145.2 & 5.3 \\
5 & 13 & 700 & 69.93 & 76.1 & 19.0 \\
6 & 27 & 700 & 1.61 & 149.2 & 8.7 \\
7 & 20 & 560 & 29.72 & 83.4 & 14.4 \\
8 & 20 & 805 & 8.83 & 123.2 & 9.9 \\
9 & 20 & 700 & 9.30 & 80.4 & 17.1 \\
10 & 20 & 700 & 9.26 & 78.6 & 14.0 \\
11 & 20 & 700 & 9.47 & 74.2 & 15.9 \\
12 & 20 & 700 & 9.61 & 77.7 & 17.5 \\
13 & 20 & 700 & 9.43 & 76.3 & 16.7 \\
\hline
\end{tabular}

${ }^{1} \mathrm{~A}$ is the drying time in the microwave $(\min ) ;{ }^{2} \mathrm{Bis}$ the powder of the microwave (Watts).

Analysis of variance (ANOVA) was performed to calculate the regression coefficient of the response surface equation and verify the validity of the RSM. The ANOVA table of response (Y) was automatically generated by the Design Expert Software (version 7.0).

Sample was dried, under the optimum conditions of powder and time determined by the routable central composite design, in a microwave oven LG model MS1742AP and finely grounded using a Krups GVX211 grinder and passed through a 40 mesh sieve $(0.42 \mathrm{~mm})$.

\subsection{Conventional Drying}

The carrot pomace obtained after juice extraction was dried in an air-oven (Linderbeg Blue $\mathrm{M}$ ) at $60^{\circ} \mathrm{C}$ during 8 $\mathrm{h}$. The dried sample was finely grounded using a Krups GVX211 grinder and passed through a 40-mesh sieve $(0.42 \mathrm{~mm})$. 


\subsection{Fiber Content}

Total dietary fiber (TDF) fractions were obtained as indigestible residues after enzymatic digestion, the insoluble residues were isolated by filtration, and soluble fiber was precipitated with ethanol. Dried residues corresponded to insoluble dietary fiber (IDF) and soluble dietary fiber (SDF), respectively.

\subsection{Scanning Electron Microscopy (SEM)}

SEM analysis was conducted as described by SánchezPardo et al. [21]. Samples from microwaved and conventionally dried carrot pomace and cookies were analyzed. Samples were examined at $1500 \times$ in a JSM 5800LV SEM (Jeol Inc., Peabody, MA, USA) at $15 \mathrm{kV}$ and $0 \mathrm{~Pa}$, equipped with an integrated program for digital image capture.

\subsection{Extraction of Bioactive Compounds and Antioxidant Activity}

Samples $(1 \mathrm{~g})$ were extracted with $20 \mathrm{~mL}$ of $80 \%$ acetone for $1 \mathrm{~h}$ with occasional stirring using a vortex mixer. The extract was centrifuged at $8000 \times \mathrm{g}$. Bioactive compounds such as carotenoids, phenolic compounds and antioxidant activity were determined in the supernatant [22].

\subsection{Total Carotenoids and Total Phenolic Compounds}

The total carotenoid content were estimated according to method described by Hernández-Ortega et al. [23]. Pigment concentration was determined spectrophotometrically at 472 and $508 \mathrm{~nm}$ wavelengths in a UV-Vis spectrophotometer (Genesys $10 \mathrm{UV}$, Thermo Scientific, Wisconsin, USA). The total phenoliccontent was estimated by the Folin-Ciocalteau method. The reaction mixture contained $100 \mu \mathrm{L}$ of sample extracts, $750 \mu \mathrm{L}$ of the FolinCiocalteu reagent, $750 \mu \mathrm{L}$ of $6 \mathrm{~g} / 100 \mathrm{~mL}$ sodium carbonate. After $90 \mathrm{~min}$ of reaction at room temperature, the absorbance at $760 \mathrm{~nm}$ was measured by a spectrophotometer (Genesys $10 \mathrm{UV}$, Thermo Scientific, Wisconsin, USA) and used to calculate the phenolic contents using gallic acid as a standard. The results are expressed as mg gallic acid equivalent per gram of dry sample [24].

\section{7. $\beta$-Carotene and Phenolic Compounds Identification}

$\beta$-carotene was identified by HPLC using a Beckman System Gold Liquid Chromatograph HPLC equipment with a model 168 photodiode array detector and the Gold Nouveau V 1.72 Chromatographic Data System (Beckman
Coulter, Fullerton, CA, USA), and a column Prodigy 5 ODS $(25 \mathrm{~cm} \times 4.6 \mathrm{~mm}$ ID, Phenomenex, Torrance, CA, USA) along with an isocratic solvent system of acetonitrile:methanol:tetrahydrofuran (THF) (58:35:7) pumped at a flow rate of $1 \mathrm{~mL} / \mathrm{min}$ for the analysis of $\beta$-carotene. Visible detection was achieved at $450 \mathrm{~nm}$ [23]. Phenolic compounds were identified using the method described by Hayat et al. [25]. The chromatographic system consisted of a Agilent Technologies G1311 binary pump and photodiode array detector (Agilent Technologies, San Diego, CA, USA). C18 column (Zorbax SB-C18, $4.6 \mathrm{~mm}$ $\times 150 \mathrm{~mm}$, Agilent Technologies, USA) was used for separation. SolventA consisted of $0.1 \%$ formic acid, and solvent B consisted of $100 \%$ methanol and the flow rate was $1 \mathrm{~mL} / \mathrm{min}$. The solvent gradient in volume ratios was as follows: 0 - $13 \mathrm{~min}, 15 \%$ - 33\% B; 13 - $21 \mathrm{~min}, 33 \%$ $39 \% \mathrm{~B} ; 21$ - $23 \mathrm{~min}, 39 \%$ - 45\% B; 23 - $25 \mathrm{~min}, 45 \% \mathrm{~B}$; 25 - 27 min, $45 \%$ - 15\% B; 27 - 33 min, 15\% B. Phenolic acids were quantified from peak area at $280 \mathrm{~nm}$.

\subsection{Antioxidant Activity: $\mathrm{DPPH}^{+}$ (2,2-Diphenyl-1-picrylhydrazil) Radical Assay}

The antioxidant activity in the acetone extracts of fresh and dried carrot pomace, and cookies added with CPPs was determined by free radical scavenging activity according to the method described by Brand-Williams et al. [26]. Each sample extract $(200 \mu \mathrm{L})$ was mixed with 1 $\mathrm{mL}$ of DPPH solution $(100 \mathrm{mM})$ and left in darkness at room temperature for $20 \mathrm{~min}$. The solution absorbance was measured at $517 \mathrm{~nm}$. The capacity to scavenge DPPH radical was calculated by the following Equation (2):

$$
\text { Scavenging activity }(\%)=1-\left(\mathrm{A}_{\mathrm{s}} / \mathrm{A}_{0}\right) \times 100
$$

where $\mathrm{A}_{0}$ is the absorbance at $517 \mathrm{~nm}$ of the blank control and $\mathrm{A}_{\mathrm{s}}$ is the absorbance of the sample.

In cookies, the percentage of free radical scavenging activity was plotted against the amount of the sample and $\mathrm{IC}_{50}$ was calculated. The half-inhibition concentration $\left(\mathrm{IC}_{50}\right)$ value was defined as the amount of sample required for $50 \%$ of free radical scavenging activity. The $\mathrm{IC}_{50}$ value was calculated from the plots as the concentration of sample required for providing $50 \%$ of the free radical scavenging activity.

\subsection{Cookies Preparation}

Raw materials were acquired in local supermarkets in Mexico City and stored in glass or plastic containers at room temperature $\left(25^{\circ} \mathrm{C} \pm 1^{\circ} \mathrm{C}\right)$ or under refrigeration according with supplier instructions. In a previous trial (data not shown), untrained panelist selected $30 \%$ as the 
maximum acceptable substitution of wheat flour for dried pomace based on cookie taste.

Cookies formulation, expressed in $\mathrm{g} / 100 \mathrm{~g}$, was: wheat flour 40.6, carrot pomace (dried in microwave oven or in conventional oven) 17.4 , water 17.4 , butter 7.3 , salt 1.5 , sugar 0.4 , baking powder 0.4 , milk powder 10.2 , fresh egg white 4.4. Dough was prepared by mixing of the ingredients in a kitchen-aid heavy-duty electric mixer (Model K5SS, Benton Harbor, MI, USA). First, butter was mixed for $2 \mathrm{~min}$ at speed level 2. Then fresh egg whites were poured into the mixer and mixed for other 2 minutes at the same speed. Carrot pomace (dried in microwave oven or in conventional oven) was added into the mix and after one minute the wheat flour was incorporated and mixed for 2 minutes at a speed level 4, the baking powder was then added and the dough was mixed for 1 minute. Milk powder was dissolved in the water and slowly incorporated and mixed until the dough was homogenous. Salt and sugar were added to the mix until 10 minutes of mixing were reached. The dough was extended immediately in order to obtain dough $2 \mathrm{~cm}$ height, and cookies were cut with a square shaped mold (2.5 $\mathrm{cm}$ diameter), and placed on greased aluminum cookie trays. The formulation was baked in a rotary oven (Henry Simon Limited, Cheshire, UK) at $180^{\circ} \mathrm{C}$ for 15 minutes and then kept in desiccators for moisture stabilization and allowed to be cooled. The cooled samples were packed in plastic bags until sensory analysis.

Chemical composition, bioactive compound content, antioxidant activity and scanning electron microscopy of the cookies were analyzed as described in prior sections. Caloric content was calculated according to the values obtained for protein, ethereal extract and non-nitrogen extract determined by proximate analysis.

\subsection{Sensory Evaluation of Cookies}

A panel consisting of 100 untrained panelists evaluated the freshly baked cookies for different sensory attributes such as color, texture, taste and overall quality.

\subsection{Statistical Analysis}

Results are expressed as mean values \pm standard deviations. Response surface data were analyzed using the Design Expert version 7.0 statistical program. Data from CPPs and cookies were processed using the software Sigma Stat (version 3.1 Systat Software Inc. San José California, USA). The analysis of variance (ANOVA) followed by Tukey test multiple comparisons were used to contrast groups. The level of significance was $95 \%$. Sensory evaluation data were evaluated with a Friedman bilateral variance rank analysis, using the Minitab software version 15 (Minitab Inc. Pennsylvania, USA).

\section{Results and Discussion}

\subsection{Optimum Conditions for Carrot Pomace Microwave Drying}

Surface response plots for moisture $\left(\mathrm{Y}_{1}\right)$, temperature $\left(\mathrm{Y}_{2}\right)$, and color $\left(\mathrm{Y}_{3}\right)$ of $\mathrm{CPD}$ in microwave oven are shown in Figures 1-3. The equations that describe the surface response behavior for moisture, temperature, and color of the CPD in microwave oven were the following:

Moisture. The two factors interaction model obtained for moisture (Equation (3)), showed a coefficient of determination of $\mathrm{R}^{2}=0.9916$ which indicate that the experimental data fit the model and presents a high level of interaction between the studied parameters. The probability of 0.0039 indicated that the variance was highly significant (Figure 1).

$$
\begin{aligned}
\mathrm{Y}_{1}= & 9.41-21.67 \mathrm{~A}-5.61 \mathrm{~B} \\
& +1.01 \mathrm{AB}+11.67 \mathrm{~A}^{2}+4.42 \mathrm{~B}^{2}
\end{aligned}
$$

where $\mathrm{Y}_{1}$ is carrot pomace moisture, $\mathrm{A}$ is drying time $(\min )$ and $\mathrm{B}$ is microwave oven powder $(\mathrm{W})$.

Temperature. The coefficient of determination $\mathrm{R}^{2}=$ 0.9824 for Equation (4), indicated that the quadratic model applied showed an optimal fit to the experimental data, the variance analysis showed a probability of 0.0084 (Figure 2).

$$
\begin{aligned}
\mathrm{Y}_{2}= & 77.44+25.80 \mathrm{~A}+11.16 \mathrm{~B} \\
& +9.25 \mathrm{AB}+16.10 \mathrm{~A}^{2}+11.42 \mathrm{~B}^{2}
\end{aligned}
$$

where $\mathrm{Y}_{2}$ is temperature, $\mathrm{A}$ is time $(\mathrm{min})$, and $\mathrm{B}$ is microwave oven powder (W).

Color. In color, the two factors interaction model obtained (Equation (5)), showed a coefficient of determination of $\mathrm{R}^{2}=0.9203$ which indicate that the model fit to the experimental data. The model variance analysis indicated that the probability was 0.049 (Figure 3).

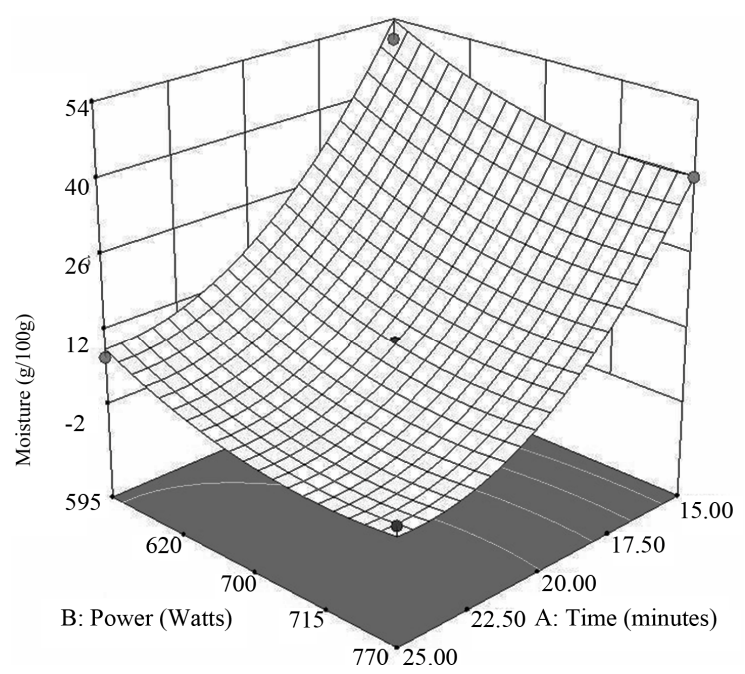

Figure 1. Effect of time and powder on the moisture of carrot pomace dried in microwave oven. 


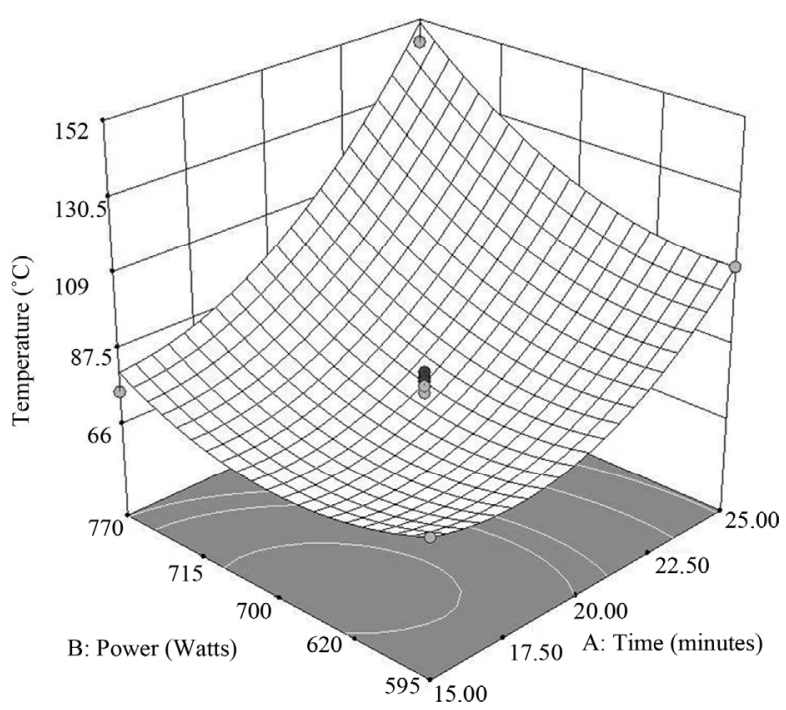

Figure 2. Effect of time and powder on the temperature of carrot pomace dried in microwave oven.

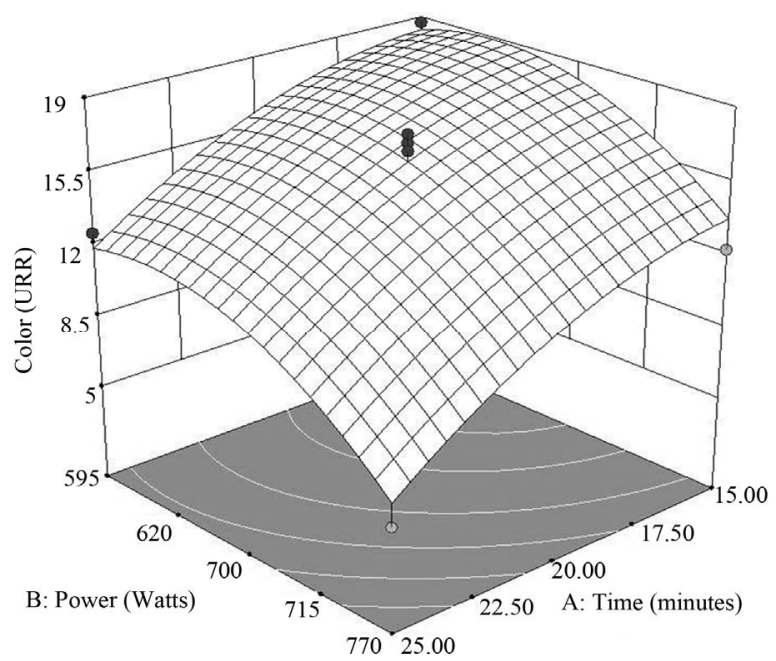

Figure 3. Effect of time and powder on the color of carrot pomace dried in microwave oven.

$$
\begin{aligned}
\mathrm{Y}_{3}= & 16.16-3.46 \mathrm{~A}-2.51 \mathrm{~B} \\
& -0.22 \mathrm{AB}-1.35 \mathrm{~A}^{2}-2.20 \mathrm{~B}^{2}
\end{aligned}
$$

where $\mathrm{Y}_{3}$ is color, $\mathrm{A}$ is drying time ( $\left.\mathrm{min}\right)$, and $\mathrm{B}$ is microwave oven powder (W).

Optimum drying conditions were obtained at a powder of $700 \mathrm{~W}$ and a time of 20 minutes.

\subsection{Fiber Content and Microstructure of the CPPS and Cookies}

Fresh and dried carrot pomaces, obtained by microwave or hot air drying, were found to be rich in total dietary fiber (TDF), $60.33 \pm 2.80,64.35 \pm 3.50$, and $64.15 \pm 3.15$ $\mathrm{g} / 100 \mathrm{~g}$, respectively. In carrot pomaces, fresh or dried, insoluble dietary fiber (IDF) was the predominant fiber fraction as IDF accounted for $79 \%$ of the total dietary fiber (Table 3). These results agree with the values reported by [5] who found that carrot pomace contained $63.5 \pm 1.15, \mathrm{~g} / 100 \mathrm{~g}$. Soluble fibers accounted for $21 \%$ of the total dietary fiber found in carrot pomaces. The consumption of insoluble fibers is beneficial to intestinal functions by enhancing intestinal peristalsis and increasing fecal bulk [1].

The substitution of $30 \%$ of the wheat flour for carrot pomace powders (CPPs) increased significantly $(\mathrm{p} \leq 0.05)$ the total dietary fiber in cookies, from $7.13 \mathrm{~g} / 100 \mathrm{~g}$ of dietary fiber to $26.44 \mathrm{~g} / 100 \mathrm{~g}$ (Table 3). The addition of $30 \%$ of either of the CPPs more than tripled the content of dietary fiber in the samples compared to the control cookie. No significant difference $(p>0.05)$ regard the fiber content was found between cookies with $30 \%$ of either carrot pomaces powders.

Various levels of dietary fiber have been reported for baked products depending on the source of fiber. Cookies containing $15 \%$ extruded orange pulp had increased dietary fiber content of $11.25 \%$, in comparison with $2.1 \%$ for the control [27]. The fiber content in breadsticks containing $15 \%, 25 \%$ and $35 \%$ Brewer's spent grain (BSG) increased significantly as the inclusion of BSG increased [28]. Similarly, the addition of $15 \%$ of dried moringa leaves powder (DMLP) increased the fiber content from $2.4 \%$ (control) to $5.3 \%$ [29].

According to FAO (2010), $25 \mathrm{~g}$ of total dietary fiber is recommended daily along with $6 \mathrm{~g}$ of soluble fiber in a 2000-calorie diet. The consumption of one cookie (7 g) baked with either CPPs will achieve the $7.4 \%$ of the daily-recommended fiber ingestion, and the $6.4 \%$ of daily intake of soluble fiber, suggesting that the substitu-

Table 3. Fiber content of carrot pomace fresh and powders, and cookies with $30 \%$ of $C P P s$.

\begin{tabular}{cccc}
\hline Sample & $\begin{array}{c}\text { Total dietary } \\
\text { fiber } \\
(\mathrm{g} / 100 \mathrm{~g} \text { d.s. })\end{array}$ & $\begin{array}{c}\text { Insoluble dietary } \\
\text { fiber } \\
(\mathrm{g} / 100 \mathrm{~g} \text { d.s. })\end{array}$ & $\begin{array}{c}\text { Soluble dietary } \\
\text { fiber } \\
(\mathrm{g} / 100 \mathrm{~g} \text { d.s. })\end{array}$ \\
\hline FCP & $60.33 \pm 0.16^{\mathrm{a}}$ & $47.66 \pm 2.21^{\mathrm{a}}$ & $12.67 \pm 0.59^{\mathrm{a}}$ \\
$\mathrm{CPM}$ & $64.35 \pm 3.50^{\mathrm{a}}$ & $51.79 \pm 2.30^{\mathrm{a}}$ & $12.56 \pm 1.20^{\mathrm{a}}$ \\
$\mathrm{CPC}$ & $64.15 \pm 3.15^{\mathrm{a}}$ & $51.68 \pm 2.39^{\mathrm{a}}$ & $12.47 \pm 0.76^{\mathrm{a}}$ \\
$\mathrm{CC}$ & $7.13 \pm 0.13^{\mathrm{b}}$ & $4.20 \pm 0.08^{\mathrm{b}}$ & $1.73 \pm 0.03^{\mathrm{b}}$ \\
$\mathrm{CCPM}$ & $26.44 \pm 0.24^{\mathrm{c}}$ & $20.89 \pm 0.19^{\mathrm{c}}$ & $5.55 \pm 0.05^{\mathrm{c}}$ \\
$\mathrm{CCPC}$ & $26.38 \pm 0.22^{\mathrm{c}}$ & $20.84 \pm 0.17^{\mathrm{c}}$ & $5.54 \pm 0.05^{\mathrm{c}}$ \\
\hline
\end{tabular}

CPPs: Carrot pomace powders, FCP: Fresh carrot pomace, CPM: Carrot pomace in microwave oven, CPC: Carrot pomace in conventional oven, $\mathrm{CC}$ : Control cookie, CCPM: Cookie with $30 \%$ of CPD in microwave, CCPC: Cookie with $30 \%$ of CPP dried in conventional oven, d.s.: dry sample. Values followed by different letters in the same row are significantly different at the 0.05 level of probability according to the Tukey test. 
tion of wheat flour for either of CPPs improve the fiber content of cookies.

The microstructure analysis of the carrot powders and cookies is shown in Figures $\mathbf{4}$ and 5. Figure 4(a) is the micrograph of fresh carrot pomace and Figures 4(b) and (c) show carrot pomace microwave oven and dried in conventional oven respectively. In Figure 4(b) it can be seen that fiber structure in the product dried in microwave oven basically maintains similar structure as fresh pomace (Figure 4(a)) while fibers in the product dried in the conventional oven (Figure 4(c)) appear as long fibers. It has been studied that microwave heating thermal process improved the capillary-porous characteristics of the raw material [30].
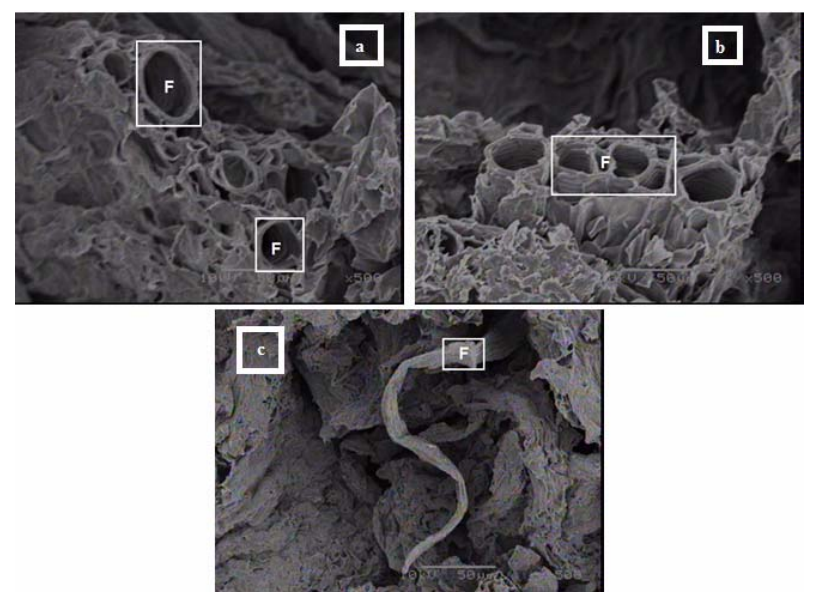

Figure 4. Microstructure $(500 \times)$ of carrot pomace after various drying method. (a) Fresh carrot pomace; (b) Microwave dried carrot pomace and (c) Conventional dried carrot pomace. $\mathbf{F}=$ Fiber.
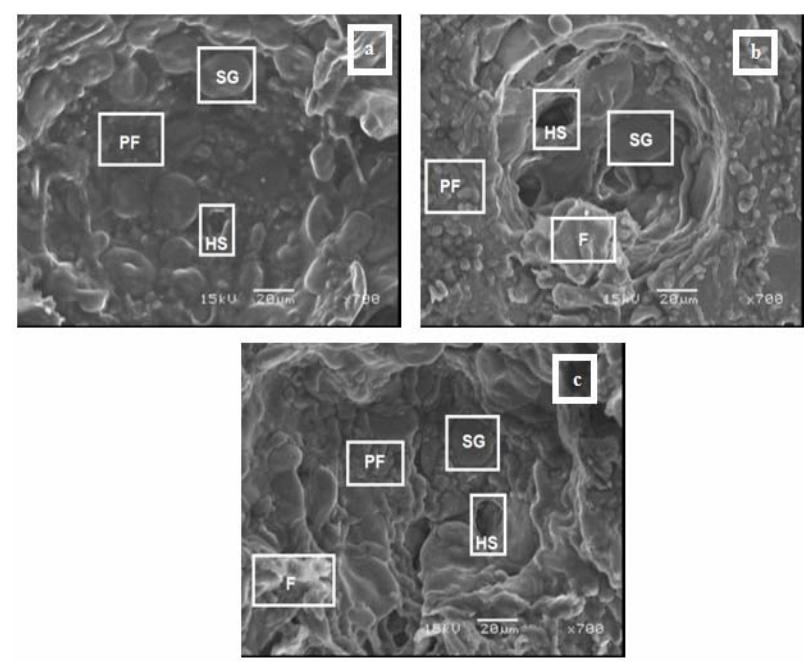

Figure 5. Microstructure $(700 \times)$ of cookies added with CPPs. (a) Control cookie; (b) Cookie added with microwave dried carrot pomace and (c) Cookie added with conventional dried carrot pomace. F: Fiber, HS: Passages, PM: Protein Matrix, SG: Starch Granules.
Figure 5(a) is the micrographs of surface of the control cookie and Figures 5(b) and (c) are the micrographs of cookies substituted with $30 \%$ of dried carrot pomace in microwave oven and conventional oven, respectively. Figure 5(a) (control cookie) shows some gelatinized starch granules (SG) trapped in protein matrix (PM). In Figures 5(b) and (c) (cookies substituted with $30 \%$ of either of carrot pomaces) can be observed fiber particles (F) adhering to starch granules and protein fibrils. In the micrographs of cookies with either of carrot pomaces powders some of the starch granules have lost the shape due to gelatinization.

Dachana and others (2010) reported that in sweet, semi-sweet biscuits and cream crackers passages of openings of various sizes were present in the material forming main structure. These passages (HS) acted as links between the cavities inside biscuits as well as between the inside of the biscuit and the atmosphere. This network of cavities and passages allow gases and steam generated in biscuits during baking to escape [29,31]. Cookies substituted with $30 \%$ of dried carrot pomace in microwave oven showed the protein matrix and starch granules without full development. Structure of cookies substituted with $30 \%$ of CPD in conventional oven resulted comparable to the structure of the control cookie.

\subsection{Phytochemical Content and Antioxidant Activity}

Carotenoid content in fresh pomace was $92.64 \pm 12.27 /$ $100 \mathrm{~g}$ dry weight (DW), meanwhile in CPD with microwaves was $74.10 \pm 4.14 \mathrm{~g} / 100 \mathrm{~g}$, and in CPP obtained with hot air was $65.74 \pm 6.49 \mathrm{~g} / 100 \mathrm{~g}$ (Table 4). The powders gotten still had a good amount of carotenoids suggesting that the use of these powders could improve the carotenoid content in different food formulation such as cookies. Nowadays, the commercial cookies consumed by population did not contain carotenoids.

As expected, the carotenoid content in cookies in which the wheat flour was substituted for either of CPPs increased significantly $(\mathrm{p} \leq 0.05)$ from $0 \mathrm{mg} / 100 \mathrm{~g}$ to 9.96 $\pm 0.64 \mathrm{mg} / 100 \mathrm{~g}$ dry sample for cookie substituted with CPP obtained in microwave oven and to $8.20 \pm 0.45 \mathrm{mg}$ $/ 100 \mathrm{~g}$ for cookie substituted with CPP gotten with hot air (Table 5). Significant difference $(p \leq 0.05)$ in the carotenoid content between cookies baked with CPPs was found. The cookie with CPP obtained with microwaves presented $17.67 \%$ more carotenoids than cookies with CPP gotten in conventional oven. According to $\mathrm{FAO} / \mathrm{OMS}, 15 \mathrm{mg}$ of carotenoids is recommended daily in a 2000-calorie diet, so the consumption of one cookie (7 g) baked with either of the CPPs will achieved approximately the $4.2 \%$ of the daily-recommended carotenoid ingestion, suggesting that CPPs could be 
Table 4. Phytochemical content and antioxidant activity of carrot pomace fresh and powders.

\begin{tabular}{cccc}
\hline Sample & $\begin{array}{c}\text { Total carotenoid } \\
\text { Content }(\mathrm{mg} / 100 \mathrm{~g} \text { d.s. })\end{array}$ & $\begin{array}{c}\text { Total phenol content } \\
(\mathrm{mg} \text { GAE/100g d.s. }\end{array}$ & $\begin{array}{c}\text { Antioxidant activity } \\
\text { DPPH assay }(\%)\end{array}$ \\
\hline FCP & $92.64 \pm 12.27^{\mathrm{a}}$ & $1841.08 \pm 40.14^{\mathrm{a}}$ & $91.8 \pm 1.77^{\mathrm{a}}$ \\
CPM & $74.10 \pm 4.14^{\mathrm{b}}$ & $1412.26 \pm 6.36^{\mathrm{b}}$ & $84.3 \pm 2.07^{\mathrm{b}}$ \\
CPC & $65.74 \pm 6.49^{\mathrm{c}}$ & $1505.35 \pm 27.5^{\mathrm{c}}$ & $82.7 \pm 1.05^{\mathrm{b}}$ \\
\hline
\end{tabular}

FCP: Fresh carrot pomace, CPM: Carrot pomace dried in microwave oven, CPC: Carrot pomace dried in conventional oven, d.s.: dry sample, GAE: Gallic acid equivalents. Values followed by different letters in the same column are significantly different at the 0.05 level of probability according to the Tukey test.

Table 5. Phytochemical content and $\mathrm{IC}_{50}$ value of cookies with carrot pomace powders.

\begin{tabular}{cccc}
\hline Sample & $\begin{array}{c}\text { Total carotenoid content } \\
(\mathrm{mg} / 100 \mathrm{~g} \text { d.s. })\end{array}$ & Total phenol content $(\mathrm{mg} \mathrm{GAE} / 100 \mathrm{~g} \mathrm{d.s.})$ & $\begin{array}{c}\mathrm{IC}_{50} \mathrm{value} \\
(\mathrm{mg})\end{array}$ \\
\hline $\mathrm{CC}$ & $0.0 \pm 0.0^{\mathrm{a}}$ & $220.83 \pm 4.10^{\mathrm{a}}$ & $790 \pm 0.08^{\mathrm{a}}$ \\
$\mathrm{CCPM}$ & $9.96 \pm 0.64^{\mathrm{b}}$ & $384.59 \pm 17.20^{\mathrm{b}}$ & $230 \pm 0.06^{\mathrm{b}}$ \\
$\mathrm{CCPC}$ & $8.20 \pm 0.45^{\mathrm{c}}$ & $346.08 \pm 1.42^{\mathrm{c}}$ & $300 \pm 0.05^{\mathrm{c}}$ \\
\hline
\end{tabular}

CC: Control cookie, CCPM: Cookie with $30 \%$ of CPD in microwave, CCPC: Cookie with $30 \%$ of CPP dried in conventional oven, d.s.: dry sample, GAE: Gallic acid equivalents. Values followed by different letters in the same column are significantly different at the 0.05 level of probability according to the Tukey test.

considered as a raw material that can improve the carotenoid content of food products.

Regard to the phenolic content, both CPPs had a lower phenolic content $(p<0.05)$ compared to the phenolic content found in fresh carrot pomace $(1505.35 \pm 27.5 \mathrm{mg}$ GAE/100g CPP obtained with microwaves and 1412.26 $\pm 6.36 \mathrm{mg}$ GAE$/ 100 \mathrm{~g}$ CPP gotten with hot air vs. $1841.08 \pm 40.14 \mathrm{mg}$ GAE$/ 100 \mathrm{~g}$ fresh carrot pomace, Table 4). The reduction could be explained since phenols are extremely sensitive to thermal treats [32-34] however, the results obtained in the present work, showed that the microwave drying reduced the phenol loose in a 5\% compared with the hot air drying.

Both cookies containing CPPs exhibited significant higher $(\mathrm{p} \leq 0.05)$ levels of total phenolic content (TPC) compared to control cookies. In cookies pomace dried in microwaves increased $74.2 \%$, and in cookies with CPD with hot air increased $56.8 \%$. Cookies with $30 \%$ of CPP obtained in microwave oven had $10 \%$ more phenolic content than cookies with air-dried CPP (Table 5).

Similar increases in the bioactive content of biscuits was observed with the addition of mango peel powder [22], dried Moringa leaves [29] and guduchi (Tinosporacordifolia) leaf powder [35].

The HPLC analysis (Table 6) revealed that CPPs, dried either with microwaves and hot air, still contains and $\beta$-carotene, finding the highest $(\mathrm{p} \leq 0.05)$ amount in microwave dried carrot pomace $(15.81 \pm 0.78 \mu \mathrm{g} / \mathrm{g} \mathrm{DW})$. Cookies with the $30 \%$ of CPP dried in microwaves had higher $(\mathrm{p} \leq 0.05)$ carotenoid content than cookies with the carrot pomace powder dried with hot air. The fact that carrot pomace still contains $\beta$-carotene after thermal processing suggested that this by product could be employed as a raw material to elaborate different foodstuffs that could help to cover the daily intake of this carotenoid.

Four phenolic compounds were identified in CPPs. Gallic acid was the main phenolic compound identified; epicatechin, catechin and ferulic acid were also present.

In cookies with CPPs, the amount of the four phenolic compounds decreased, but it is important to observed (Table 6) that epicatechin, and important flavanol with health related benefits [36], is still present at cookies with $30 \%$ of carrot pomace powder dried in microwaves, suggesting that this drying method helps to preserved important phenolic compounds with health related benefits.

Regard to the antioxidant activity, fresh carrot pomace generated $91.8 \%$ of DPPH inhibition; this activity was reduced $(\mathrm{p} \leq 0.05)$ in an $8.2 \%$ with microwave drying until reach $84.3 \%$ of DPPH inhibition (Table 4). The hot air-drying also reduced the antioxidant activity, generating a $10 \%$ loss, and reaching $82.7 \%$ of DPPH inhibition. The reduction in the antioxidant activity after drying process might be associated to the reduction on the carotenoid and total phenolic contents, because the phytochemicals, carotenoids and phenolic compounds, were reduced in $20 \%$ with microwave drying and in $25 \%$ with hot air drying. No difference between CPPs was found regard to the antioxidant activity.

In cookies, the amount of cookie required to obtain the $50 \%$ DPPH radical scavenging activity $\left(\mathrm{IC}_{50}\right.$ value) was $230 \mathrm{mg}$ for the cookie incorporated with $30 \%$ of microwave dried CPP and $300 \mathrm{mg}$ of cookie with hot air dried while it was $790 \mathrm{mg}$ in case of control cookie (Table 5). The substitution of wheat flour for either of CPPs reduced in a $66 \%$ the quantity needed to inhibit the fifty percent of the DPPH activity, showing and improvement 
Table 6. Phytochemical content $\mu \mathrm{g} / \mathrm{g} \mathrm{DW}$ in carrot pomace powders and cookies.

\begin{tabular}{cccccc}
\hline Sample & $\beta$-carotene & Epicatechin & Catechin & Gallic acid & Ferulic acid \\
\hline CPM & $15.81 \pm 0.78^{\mathrm{a}}$ & $4.36 \pm 0.06^{\mathrm{a}}$ & $8.49 \pm 0.36^{\mathrm{a}}$ & $1019.8 \pm 28.8^{\mathrm{a}}$ & $7.97 \pm 0.11^{\mathrm{a}}$ \\
CPC & $6.83 \pm 0.29^{\mathrm{b}}$ & $5.64 \pm 0.04^{\mathrm{b}}$ & $5.61 \pm 0.24^{\mathrm{b}}$ & $1048.9 \pm 7.4^{\mathrm{a}}$ & $2.49 \pm 0.05^{\mathrm{b}}$ \\
$\mathrm{CCPM}$ & $2.13 \pm 0.08^{\mathrm{c}}$ & $0.19 \pm 0.001^{\mathrm{c}}$ & $\mathrm{ND}$ & $137.5 \pm 4.9^{\mathrm{b}}$ & $5.71 \pm 0.24^{\mathrm{c}}$ \\
$\mathrm{CCPC}$ & $0.85 \pm 0.02^{\mathrm{d}}$ & $\mathrm{ND}$ & $\mathrm{ND}$ & $141.6 \pm 6.0^{\mathrm{b}}$ & $0.99 \pm 0.04^{\mathrm{d}}$ \\
\hline
\end{tabular}

DW: Dry weight, CPM: Carrot pomace in microwave oven, CPC: Carrot pomace in conventional oven, CC: Control cookie, CCPM: Cookie with $30 \%$ of carrot pomace dried in microwave, CCPC: Cookie with 30\% of carrot pomace in conventional oven, ND: No detectable. All data are the mean \pm SD. Mean followed by different letters in the same column differs significantly $(\mathrm{p}<0.05)$.

in the antioxidant activity with the addition of the CPPs. Similar results regard to the increase in the antioxidant activity was found in cookies baked with mango peel powder [22,37].

The antioxidant activity increased in the cookies with CPPs compared with the control cookie may be attributed to the rise in the content of carotenoids and phenolic compounds, due to the phytochemical content significantly increased $(p \leq 0.05)$ in a $79 \%$ with the use of CPP dried in microwave oven and in $60 \%$ with the CPP obtained by hot-air drying.

The differences found in phytochemical content and antioxidant activity between cookies might be attributed to the influence of the heat treatment in the structure of carrot pomace, as can be seen in Figure 4(b) the fiber structure remains intact in pomace dried with microwaves compared to the microstructure of CPP obtained with hot air (Figure 4(c)), suggesting that the fiber well define structure observed in CPD in microwave oven could protect the phytochemicals after a severe heat treatment such as baking process.

\subsection{Sensorial Analysis of Cookies}

Both cookies formulated with the CPPs exhibited an improvement in the crust color, $60 \%$ with CPP microwaved and 20\% with CPP obtained with hot air. Control cookie had a creamy white color (Figure 6), while cookies prepared with CPD with microwaves and hot air had an orange color and yellowish brown color respectively. The improvement in the color of cookies could be attributed to the increased in the carotenoid content.

Cookies texture was improved in a $40 \%$ with the CPP obtained by microwave drying and $20 \%$ for CPP gotten with hot air (Table 7). The samples added with CPPs became relatively softer compared to the control cookie, this might be due to the high swelling property capacity of the carrot pomace $[3,5]$. The biscuits in which flour was replaced in a $30 \%$ for either of CPPs had a pleasant sweet flavor. CPPs help to improve the taste of the cookies in $18.8 \%$ with the addition of microwaved dried car rot pomace and in $12.5 \%$ with the addition of CPP from hot air drying. The cookie added with the CPP dried with

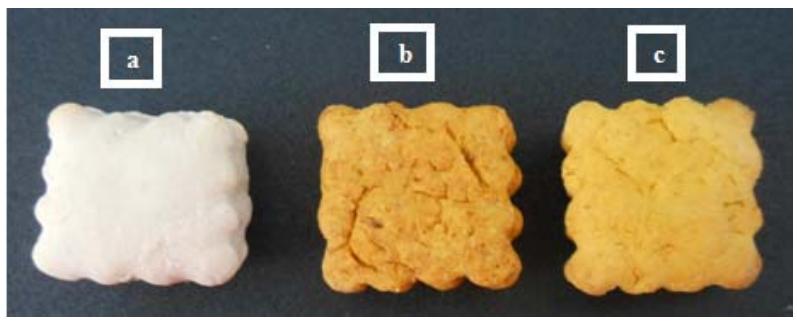

Figure 6. Cookies with carrot pomace powders. (a) Control cookie; (b) Cookie with carrot pomace dried in microwaves; (c) Cookie with carrot pomace dried with hot air.

Table 7. Influence of CPP on the sensory acceptability of cookie.

\begin{tabular}{ccccc}
\hline Sample & Color & Texture & Taste & Overall Quality \\
\hline CC & $5.0 \pm 0.5^{\mathrm{a}}$ & $5.0 \pm 0.6^{\mathrm{a}}$ & $8.0 \pm 0.5^{\mathrm{a}}$ & $5.0 \pm 0.1^{\mathrm{a}}$ \\
CCPM & $8.0 \pm 0.5^{\mathrm{c}}$ & $7.0 \pm 0.5^{\mathrm{b}}$ & $9.5 \pm 0.4^{\mathrm{b}}$ & $8.0 \pm 0.4^{\mathrm{b}}$ \\
CCPC & $6.0 \pm 0.9^{\mathrm{b}}$ & $6.0 \pm 0.5^{\mathrm{a}}$ & $9.0 \pm 0.6^{\mathrm{b}}$ & $5.0 \pm 0.4^{\mathrm{a}}$ \\
\hline
\end{tabular}

CC: Control cookie, CCPM: Cookie with $30 \%$ of carrot pomace dried in microwave, CCPC: Cookie with $30 \%$ of carrot pomace in conventional oven. Rating in general: Very good-10, Good-8, Fair-6, Poor-4, Very poor -2 . All data are the mean \pm SD. Mean followed by different letters in the same column differs significantly $(\mathrm{p}<0.05)$.

microwaves received the highest acceptance because an $88 \%$ of the panelists gave a qualification "good" to the cookie added with the CPP obtained by microwave drying.

It is noteworthy that the replacement of wheat flour for CPPs significantly $(\mathrm{p} \leq 0.05)$ reduced in a $23 \%$ the caloric content of cookies. Control cookies had a caloric content of $368.38 \mathrm{~kJ} / 100 \mathrm{~g}$, meanwhile cookie with microwave dried CPP had $274.24 \mathrm{~kJ} / 100 \mathrm{~g}$ and cookie with hot air dried carrot pomace had $275.15 \mathrm{~kJ} / 100 \mathrm{~g}$.

\section{Conclusion}

Substitution of wheat flour for either of carrot pomace powders increased the dietary fiber and carotenoid content in cookies, and also helped to reduce the caloric content of cookies, suggesting these could be employed as raw materials to produce foodstuff high in fiber, with improving phytochemical content and low in calories. 


\section{Acknowledgements}

This research was funded by Consejo Nacional de Ciencia y Tecnología (CONACyT) scholarship 202204 and Secretaría de Investigación y Posgrado-Instituto Politécnico Nacional, project numbers 20100788, 20110922, and 20120177. We thank L. Trejo-Gómez Orozco for assistance with statistical analysis.

\section{REFERENCES}

[1] C. Nicolle, N. Cardinault, O. Aprikian, J. Busserolles, P. Grolier, E. Rock, C. Demigné, A. Mazur, A. Scalbert, P. Amouroux and C. Rémésy, "Effect of Carrot Intake on Cholesterol Metabolism and on Antioxidant Status in Cholesterol-Fed Rat," European Journal of Nutrition, Vol. 42, No. 5, 2003, pp. 254-261. http://dx.doi.org/10.1007/s00394-003-0419-1

[2] T. Stoll, U. Schweiggert, A. Schieber and R. Carle, "Application of Hydrolyzed Carrot Pomace as a Functional Food Ingredient to Beverages," Journal of Food Agriculture and Environment, Vol. 1, No. 2, 2003, pp. 88-92.

[3] P. Chantaro, S. Devahastin and N. Chiewchan, "Production of Antioxidant High Dietary Fiber Powder from Carrot Peels," LWT-Food Science and Technology, Vol. 41, No. 10, 2008, pp. 1987-1994.

[4] K. Y. Yoon, M. Cha, S. R. Shin and K. S. Kim, "Enzymatic Production of a Soluble-Fibre Hydrolyzate from Carrot Pomace and Its Sugar Composition," Food Chemistry, Vol. 92, No. 1, 2005, pp. 151-157. http://dx.doi.org/10.1016/j.foodchem.2004.07.014

[5] C. F. Chau, C. H. Chen and M. H. Lee, "Comparison of the Characteristics, Functional Properties, and in Vitro Hypoglycemic Effects of Various Carrot Insoluble Fiber-Rich Fractions," LWT-Food Science and Technology, Vol. 37, No. 2, 2004, pp. 155-160.

[6] C. Alklint, "Carrot Juice Processing: Effects on Various Quality Aspects," Bulletin, Lund Institute of Technology, Lund University, Lund, 2003.

[7] K. Sharma, S. Karki, N. Thakur and S. Attri, "Chemical Composition, Functional Properties and Processing of Carrot-A Review," Journal of Food Science and Technology, Vol. 49, No. 1, 2012, pp. 22-32. http://dx.doi.org/10.1007/s13197-011-0310-7

[8] A. Nawirska and M. Kwaśniewska, "Dietary Fibre Fractions from Fruit and Vegetable Processing Waste," Food Chemistry, Vol. 91, No. 2, 2005, pp. 221-225. http://dx.doi.org/10.1016/j.foodchem.2003.10.005

[9] N. Balasundram, K. Sundram and S. Samman, "Phenolic Compounds in Plants and Agri-Industrial By-Products: Antioxidant Activity, Occurrence, and Potential Uses," Food Chemistry, Vol. 99, No. 1, 2006, pp. 191-203. http://dx.doi.org/10.1016/j.foodchem.2005.07.042

[10] E. Kiassos, S. Mylonaki, D. P. Makris and P. Kefalas, "Implementation of Response Surface Methodology to Optimise Extraction of Onion (Allium cepa) Solid Waste Phenolics," Innovative Food Science and Emerging Technologies, Vol. 10, No. 2, 2009, pp. 246-252. http://dx.doi.org/10.1016/j.ifset.2008.10.004
[11] J. L. Bauer, B. Harbaum-Piayda and K. Schwarz, "Phenolic Compounds from Hydrolyzed and Extracted FiberRich By-Products," LWT-Food Science and Technology, Vol. 47, No. 2, 2012, pp. 246-254.

[12] J. F. Ayala-Zavala, V. Vega-Vega, C. Rosas-Domínguez, H. Palafox-Carlos, J. A. Villa-Rodriguez, M. W. Siddiqui, J. E. Dávila-Aviña and G. A. González-Aguilar, "AgroIndustrial Potential of Exotic Fruit Byproducts as a Source of Food Additives," Food Research International, Vol. 44, No. 7, 2011, pp. 1866-1874. http://dx.doi.org/10.1016/j.foodres.2011.02.021

[13] R. Martínez, P. Torres, M. A. Meneses, J. G. Figueroa, J. A. Pérez-Álvarez and M. Viuda-Martos, "Chemical, Technological and in Vitro Antioxidant Properties of Mango, Guava, Pineapple and Passion Fruit Dietary Fibre Concentrate," Food Chemistry, Vol. 135, No. 3, 2012, pp. $1520-1526$. http://dx.doi.org/10.1016/j.foodchem.2012.05.057

[14] Á. Calín-Sánchez, A. Figiel, F. Hernández, P. Melgarejo, K. Lech and Á. Carbonell-Barrachina, "Chemical Composition, Antioxidant Capacity, and Sensory Quality of Pomegranate (Punica granatum) Arils and Rind as Affected by Drying Method," Food and Bioprocess Technology, Vol. 6, No. 7, 2012, pp. 1-11.

[15] L. Gilbert, "The Consumer Market for Functional Foods," Journal of Nutraceuticals, Functional and Medical Foods, Vol. 1, No. 3, 1997, pp. 5-21.

[16] D. Fussenegger, A. Pietrobelli and K. Widhalm, "Childhood Obesity: Political Developments in Europe and Related Perspectives for Future Action on Prevention," Obesity Reviews, Vol. 9, No. 1, 2008, pp. 76-82.

[17] D. S. Freedman, D. A. Patel, S. R. Srinivasan, W. Chen, R. Tang, M. G. Bond and G. S. Berenson, "The Contribution of Childhood Obesity to Adult Carotid Intima-Media Thickness: The Bogalusa Heart Study," International Journal of Obesity, Vol. 32, No. 5, 2008, pp. 749-756. http://dx.doi.org/10.1038/sj.ijo.0803798

[18] Y. Wang, X. Chen, M. J. Klag and B. Caballero, "Epidemic of Childhood Obesity: Implications for Kidney Disease," Advances in Chronic Kidney Disease, Vol. 13, No. 4, 2006, pp. 336-351. http://dx.doi.org/10.1053/j.ackd.2006.07.016

[19] M. U. Arshad, F. M. Anjum and T. Zahoor, "Nutritional Assessment of Cookies Supplemented with Defatted Wheat Germ," Food Chemistry, Vol. 102, No. 1, 2007, pp. 123-128. http://dx.doi.org/10.1016/j.foodchem.2006.04.040

[20] N. Bilgiçli, Ş. İbanog`lu and E. N. Herken, "Effect of Dietary Fibre Addition on the Selected Nutritional Properties of Cookies," Journal of Food Engineering, Vol. 78, No. 1, 2007, pp. 86-89. http://dx.doi.org/10.1016/j.jfoodeng.2005.09.009

[21] M. E. Sánchez-Pardo, A. Ortiz-Moreno, R. Mora-Escobedo, J. J. Chanona-Pérez and H. Necoechea-Mondragón, "Comparison of Crumb Microstructure from Pound Cakes Baked in a Microwave or Conventional Oven," $L W T$ Food Science and Technology, Vol. 41, No. 4, 2008, pp. 620-627.

[22] C. M. Ajila, K. Leelavathi and U. J. S. Prasada Rao, "Im- 
provement of Dietary Fiber Content and Antioxidant Properties in Soft Dough Biscuits with the Incorporation of Mango Peel Powder," Journal of Cereal Science, Vol. 48, No. 2, 2008, pp. 319-326.

http://dx.doi.org/10.1016/j.jcs.2007.10.001

[23] M. Hernández-Ortega, A. Ortiz-Moreno, M. D. HernándezNavarro, G. Chamorro-Cevallos, L. Dorantes-Alvarez and H. Necoechea-Mondragón, "Antioxidant, Antinociceptive, and Anti-Inflammatory Effects of Carotenoids Extracted from Dried Pepper (Capsicum annuum L.)," Journal of Biomedicine and Biotechnology, Vol. 2012, No. 524019, 2012, pp. 1-10. http://dx.doi.org/10.1155/2012/524019

[24] M. E. Jaramillo-Flores, L. González-Cruz, M. CornejoMazón, L. Dorantes-Alvarez, G. F. Gutiérrez-López and H. Hernández-Sánchez, "Effect of Thermal Treatment on the Antioxidant Activity and Content of Carotenoids and Phenolic Compounds of Cactus Pear Cladodes (Opuntia ficus-indica)," Food Science and Technology International, Vol. 9, No. 4, 2003, pp. 271-278. http://dx.doi.org/10.1177/108201303036093

[25] K. Hayat, X. Zhang, H. Chen, S. Xia, C. Jia and F. Zhong, "Liberation and Separation of Phenolic Compounds from Citrus Mandarin Peels by Microwave Heating and Its Effect on Antioxidant Activity," Separation and Purification Technology, Vol. 73, No. 3, 2010, pp. 371-376. http://dx.doi.org/10.1016/j.seppur.2010.04.026

[26] W. Brand-Williams, M. E. Cuvelier and C. Berset, "Use of a Free Radical Method to Evaluate Antioxidant Activity," LWT_Food Science and Technology, Vol. 28, No. 1, 1995, pp. 25-30.

[27] M. A. Larrea, Y. K. Chang and F. Martinez-Bustos, "Some Functional Properties of Extruded Orange Pulp and Its Effect on the Quality of Cookies," LWT-Food Science and Technology, Vol. 38, No. 3, 2005, pp. 213-220.

[28] A. Ktenioudaki, V. Chaurin, S. F. Reis and E. Gallagher, "Brewer's Spent Grain As a Functional Ingredient for Breadsticks," International Journal of Food Science \& Technology, Vol. 47, No. 8, 2012, pp. 1765-1771. http://dx.doi.org/10.1111/j.1365-2621.2012.03032.x

[29] K. B. Dachana, J. Rajiv, D. Indrani and J. Prakash, "Effect of Dried Moringa (Moringa oleifera Lam) Leaves on Rheological, Microstructural, Nutritional, Textural and Organoleptic Characteristics of Cookies," Journal of Food Quality, Vol. 33, No. 5, 2010, pp. 660-677. http://dx.doi.org/10.1111/j.1745-4557.2010.00346.x
[30] M. Kratchanova, E. Pavlova and I. Panchev, "The Effect of Microwave Heating of Fresh Orange Peels on the Fruit Tissue and Quality of Extracted Pectin," Carbohydrate Polymers, Vol. 56, No. 2, 2004, pp. 181-185. http://dx.doi.org/10.1016/j.carbpol.2004.01.009

[31] K. Nandeesh, R. Jyotsna and G. Venkateswara Rao, "Effect of Differently Treated Wheat Bran on Rheology, Microstructure and Quality Characteristics of Soft Dough Biscuits," Journal of Food Processing and Preservation, Vol. 35, No. 2, 2011, pp. 179-200. http://dx.doi.org/10.1111/j.1745-4549.2009.00470.x

[32] J. C. Rickman, D. M. Barrett and C. M. Bruhn, "Nutritional Comparison of Fresh, Frozen and Canned Fruits and Vegetables. Part 1. Vitamins C and B and Phenolic Compounds," Journal of the Science of Food and Agriculture, Vol. 87, No. 6, 2007, pp. 930-944. http://dx.doi.org/10.1002/jsfa.2825

[33] A. Ruiz-Rodriguez, F. Marín, A. Ocaña and C. SolerRivas, "Effect of Domestic Processing on Bioactive Compounds," Phytochemistry Reviews, Vol. 7, No. 2, 2008, pp. 345-384. http://dx.doi.org/10.1007/s11101-007-9073-1

[34] D. M. Barrett and B. Lloyd, "Advanced Preservation Methods and Nutrient Retention in Fruits and Vegetables," Journal of the Science of Food and Agriculture, Vol. 92, No. 1, 2012, pp. 7-22. http://dx.doi.org/10.1002/jsfa.4718

[35] P. Sharma, V. Velu, D. Indrani and R. P. Singh, "Effect of Dried Guduchi (Tinospora cordifolia) Leaf Powder on Rheological, Organoleptic and Nutritional Characteristics of Cookies," Food Research International, Vol. 50, No. 2, 2013, pp. 704-709. http://dx.doi.org/10.1016/j.foodres.2012.03.002

[36] P. C. H. Hollman and I. C. W. Arts, "Flavonols, Flavones and Flavanols-Nature, Occurrence and Dietary Burden," Journal of the Science of Food and Agriculture, Vol. 80, No. 7, 2000, pp. 1081-1093.

http://dx.doi.org/10.1002/(SICI)1097-0010(20000515)80: 7<1081::AID-JSFA566>3.0.CO;2-G

[37] F. Zucco, Y. Borsuk and S. D. Arntfield, "Physical and Nutritional Evaluation of Wheat Cookies Supplemented with Pulse Flours of Different Particle Sizes," LWTFood Science and Technology, Vol. 44, No. 10, 2011, pp. 2070-2076. 